\title{
Public-Private ICT-Based Collaboration Initiative During the COVID-19 Pandemic: The Case of Ehsaas Emergency Cash Program in Pakistan
}

Anil Yasin $\mathbf{A r}^{1}$

https://orcid.org/0000-0002-0291-7862

Asad Abbas ${ }^{\star}$
https://orcid.org/0000-0003-1395-4009

${ }^{1}$ Tecnológico de Monterrey, Department of International Business and Logistics, Queretaro, Mexico; ${ }^{2}$ Tecnológico de Monterrey, Writing Lab, Institute for the Future of Education, Monterrey, Nuevo León, Mexico.

Editor-in-Chief: Paulo Vitor Farago

Associate Editor: Bruno Pedroso

Received: 2020.09.24; Accepted: 2021.05.04.

*Correspondence: asad.abbas@tec.mx; Tel.: +52-8123216091 (A. A.).

\section{HIGHLIGHTS}

- Case study approach is used to explore ICT-based collaboration initiative in Pakistan.

- Collaboration between NADRA, SBP and local commercial banks, and telecom sector during the COVID-19.

- Mobile fund transfer under "Ehsaas Emergency Cash" program.

- Study contributes with COVID19, ICT, e-government, and cross sectoral collaboration.

Abstract: The purpose of this study is to explore the application of the Pakistani government's ICT-based public-private collaboration strategy during the COVID-19 pandemic. This investigation covers the Ehsaas Emergency Cash (EEC) program, from the beginning of the application to receiving of funds, which was developed by a collaborative mechanism involving the Pakistani government, National Database and Registration Authority (NADRA), State Bank of Pakistan (SBP), local commercial banks and the telecom sector. By investigating the EEC via the case study method, this paper provides insights to policymakers on how to replicate similar strategies in various country contexts via leveraging public-private collaboration, ICT technologies, and policymaking. This study contributes the COVID-19, ICT, e-government, and public-private collaboration literature via providing insight about current events and a model based on the case presented.

Keywords: COVID-19; educational innovation; e-governance; ICT policy; public-private collaboration.

\section{INTRODUCTION}

Technological advances in information and communication technologies (ICT) within the public sector have morphed governments' relationship with their citizens, private sectors, and other societal actors [1]. The rapid increase in urbanization [2] and private sectors' shift towards e-commerce, both of which necessitates quick and reliable information share among various players in an economy, work as a catalyst in this 
transformation and further motivate the e-revolution in the various layers of governments [1-2]. The pressing need of this transformation, both in developed and developing countries, have escalated governments' effort to convert their manual processes to digital ones through leveraging these technologies [3]. Thus, aiming to serve the private industry as well as the society in an efficient manner, ICTs become the cornerstone for nations that are aiming to operate smoothly in a multi-stakeholder environment [4].

A multi-stake holder environment, which can be defined as an economy that "involve[s] actors from several spheres of society (market, civil society and state) in collaborative arrangements" [5], requires governments as well as all participating parties to establish novel approaches to deal with complex problems. By their nature, complex problems usually cannot be solved by a sole institution or a private party. Interorganizational collaboration and public-private involvements are imperative to overcome them [6-7]. Interorganizational collaboration refers to two or more organizations working on a project, whereas public-private collaboration involves multiple different sectors, such as, the public and private sectors in either at the same economy or across the borders [8]. ICTs answer these needs by providing new opportunities in terms of supporting public-private the integration and ability to architect new business models to provide a platform [9]. These platforms enable involving sectors and firms to work together in an efficient way towards creating value in compliance with government policies and R\&D activities [10]. As a result, public-private and interorganizational projects ensure improvements in governance, management, resource (technical and nontechnical) allocation, and overall socio-economic success of government-based projects $[3,5]$.

The struggle with ICT projects is, on the other hand, a nation's ability to develop technological capabilities while sustaining the infrastructural investments to support ICT-based collaborations simultaneously. Implementing of new technologies requires a substantial amount of human, financial, and time capital [11]. They are not readily available at each nations' disposal. Thus, it could be inferred that the success of publicprivate projects and their successful execution depend heavily on the macro-economic as well as socioeconomic conditions of a country [12].

Yet, evidence and recent ICT practices demonstrate that even though macro and socio-economic conditions are the most prominent determinants, they are not the sole factors for a successful ICT implementation. For instance, one may expect that developed nations have more means (human and financial capital) to realize new e-government platforms as well as initiate advanced technologic infrastructures to transform their governments as opposed to their developing counterparts. However, contrary to expectations, developing countries' leapfrogging strategies in the field of e-government enable them to lead the advancements of ICT-based public-private government projects [13]. The latest United Nations E-government Development Index revealed that two of the top three e-government advancement levels belong to two emerging economies, namely Republic of Korea and Estonia [14].

In the time of COVID-19, initiatives that are taken by the emerging or developing country governments, with the support of public-private initiatives, provide further evidence. The literature suggests that private, governmental, and civil society players provide local knowledge and connection to diverse networks, which contribute to more successful and efficient disaster response functions while promoting transparency [1516]. In alignment with that train of thought, many countries try to implement public-private collaborations through leveraging ICTs. Governments force to come up with effective ICT-based strategies that involve different societal sectors and stakeholders in a short span of time. This put pressure on governments and institutions to design and execute new e-services to support their citizens, who are dealing with COVID-19 and the negativities that are caused by it.

Yet, the relevant literature has not explored the full extent of ICT strategies that are employed by state and private sector players in the context of public-private collaborations. This literature gap has become even more significant and widened due to the newly introduced struggles by COVID-19, especially in the context of emerging market countries. This study, henceforward, motivated to contribute the literature through a case study that explores the COVID-19 adverse effects and how an emerging market country, namely Pakistan, leverages ICT capabilities to create a relief program based on public-private industry collaboration. The scope of the study is explicitly determined to answer the subsequent research question; "how does Pakistan utilize public-private collaboration strategies during COVID-19 in order to support Pakistani citizens?" In order to provide an in-depth understanding and rigorous conceptualization, this study leverages the case study approach to investigate how the Pakistani government succeeds creating an efficient ICT strategy to aid citizens of Pakistan who are adversely affected by COVID-19. 


\section{Background}

Confronted with the COVID-19 pandemic, administrations around the globe have taken initiatives to protect their citizens from the pandemic's adverse effects and support their resilience during and post-disaster circumstances. In just a few months, a large number of countries around the globe have been heavily affected by COVID-19 in terms of health, business, education, and many other aspects of life [17]. The first case of COVID-19 was observed in the city of Wuhan in China in 2019 December [18]. It quickly spread out and infected 75,000 Wuhan residents. As a preventative measure, the Chinese government decided to engage with a lockdown strategy in Hubei province, including its 15 cities [19]. But afore the execution of strict quarantine measures and lockdown, the virus spread across the Chinese borders in a very short amount of time. International organizations and supranational such as the World Health Organization (WHO) and governments of almost all countries began using digital technologies. They use multi-media channels and mobile technologies to share the latest information available on COVID-19 and its effects on their societies and socio-economic activities. As a result, ICT has gained more attention. It evolved from being a supplementary tool to a chief instrument of governmental policy and decision-making process in the time of the COVID-19 crisis. This is especially the case for the developing countries, which are putting the digitalization of processes at the top of their agendas to decrease the number of people who are in need to leave their homes. It helps governments to keep the spread of COVID-19 under control as much as possible and reinforces the social distancing measures.

The latest COVID-19 figures illustrate that Pakistan is one of the countries which as significantly impacted by the on-going pandemic [20]. Government COVID-19 statistics confirm a total of 181,087 cases, with 71,458 recovered and 3,590 reported dead [21]. COVID-19 affects people in terms of social isolation and distancing and as a result of the economic recession [22-23]. COVID-19's negative socio-economic impacts cause millions of job losses in Pakistan's economy, and IMF is projecting that the job loss surge will continue to grow despite the positive signs of economic recovery [24, 25]. In this time of crisis, the government of Pakistan took the initiative and launched a relief package - the "Ehsaas Emergency Cash" (EEC) program to financially support low-income families [26] that have no source of income and face the lockdown situation. The government-offered relief program is based on a public-private collaboration strategy, an approach that involves both public and private stakeholders such as the National Database and Registration Authority (NADRA), telecom, state and local commercial banking sector.

\section{MATERIAL AND METHODS}

\section{Methodology}

The case study approach has been employed to study how current events unfold through phases and what type of effect they create in different settings. While the method itself being a robust observation-based inquiry, it is an effective tool to combine literature and real-life events beyond the developed theoretical frameworks $[27,28,29]$. This is especially the case for the newly occurring events, phenomena, and developments [30]. This is simply due to the case study method's advantage in transforming a novel event to a comprehension, which can be replicated by others as well as used as a theoretical springboard.

According to Eisenhardt (1989) [31], the case study is especially appropriate and adequate if it is employed at either one or the combination of the following situations: (1) if the current perspective seems inadequate, (2) if there is still inconclusive evidence, (3) if the current events contradict with the already established theories. The method puts emphasis on the underlying reasons, ties, and causal relationships, unlike its quantitative approaches that are focusing on correlations or coefficient values [32, 33]. Hence, it accomplishes to contribute literature gaps and illustrates the significance of the current events.

The given study, following the aforementioned literature, utilizes the case study technique to articulate the current happenings and bridge the literature with these observations. This is due to the case study method's strength in exploring and investigating how public-private collaborating take place while answering the following inquiries: (1) how multiple entities interact with each other in building and governing EEC; (2) what is the process of information exchange; (3) how are the process of decision-making activities take place; and (4) what is the process of exchanging feedbacks among multiple collaborators? This ensures the reflection of the dynamic nature of the EEC program and the case in hand. The reason why the Pakistan and the EEC are chosen is due to Pakistan's leading role in South Asia. In addition, the country is one of the pioneers which utilizes public-private collaboration in the context of COVID-19. It represents a unique opportunity to observe how an emerging market country substantializes a complex collaboration structure based upon ICT availability in the country in the face of an adverse event. 


\section{The case: Ehsaas Emergency Cash program}

As a preventative measure against the quickly spreading COVID-19, the Pakistani government design and launch a financial care incentive, namely "Ehsaas Emergency Cash" program, for low-income citizens. "Ehsaas" (سلسح), meaning "feeling" in Urdu language, gives a way for the government to rich to its Pakistani citizens in need and share their "feeling[s]" in the face of hardship amid the pandemic. Aiming to fiscally support low-income citizens who either lose their employments or daily earnings, the government design Ehsaas to prevent the further negativities that may occur due to the quarantine measures and support its citizens who are significantly impacted by the ongoing pandemic. In April 2020, the Prime Minister of Pakistan, Imran Khan, broadcast the launch of Ehsaas across the country [26]. Initially, the government allocated 144 million Pakistani rupees (PKR) to support eighteen million households, with the aim of providing 12,000 PKR per family on a monthly basis [23].

The EEC initiative is dispensed via an online platform, enabling families and citizens to check their eligibility through SMS service and register for financial support in case the system indicates a positive eligibility status. Alternatively, qualified claimants can reach a District Administration through text-messages for registration and get their claims recorded into the online portal. If either way is not feasible to the individuals, they can visit the nearest District Administration office in person to complete the procedures and paperwork to get registered. This system is made available through a close collaborative work among NADRA, SBP, local commercial banks, the telecom sector as well as the Pakistani government.

\section{National database and registration authority (NADRA)}

One of the first steps towards e-governance taken by Pakistan was establishing the National Database Organization (NDO) in 1998. In 2000, it was followed by the NDO and the Directorate General of Registration merger, which established what is known as "The National Database and Registration Authority" (NADRA). The organization is a successful implementation of e-governance tools in Pakistan. It maintains the role of a centralized data warehouse while offering various of e-services to Pakistani citizens living in the country or abroad. Some of such services are Computerized National Identity Card (CNIC), birth certificates, family registration certificates (FRC) [34], which eases the further development of biometric verification systems.

A biometric verification system that is employed by the government is the cornerstone of functionality for citizens of Pakistan who are wishing to utilize NADRA services. The NADRA system caters an e-platform to service providers in Pakistan through facilitating and providing biometric authentication services to the banking sector, the telecom sector, and various government departments to verify Pakistani citizen's records for the purposes of mobile connection (SIM registration and verification), online passport application (registration and verification), and mobile banking.

\section{Mobile fund transfer technologies}

With the surge of mobile technology usage, in 2009, the mobile banking sector is established in Pakistan. Even though it may seem relatively recent, the exponentially growing telecommunication and mobile device usage data, now more than 140 million people are users of mobile phones, put Pakistan on the eighth row in the world for mobile technology usage [35]. Therefore, it provides a lucrative business field for the finance industry and banking sector.

Yet, barriers to mobile banking and e-banking are present in the country. Including but not limited to lack of knowledge on the existing technology, confidence, state of connectedness, and perceived risk put stress on the mobile technologies in the nation [36]. Despite the existence of these barriers, the government of Pakistan moves forward with the use of mobile fund transferring methods for the EEC program to transmit and allocate funding to qualified citizens. Working in collaboration with the government, four mobile service providers currently offer fund transferring (SMS message with code while capturing biometric data) in Pakistan - Jazz, Telenor, Zong, and Ufone. Companies utilize NADRA services to retrieve and check biometric information. Additionally, they require CNIC copies to establish a mobile connection for the completion of a mobile remittance. Since the mobile fund transferring method is previously introduced to the banking systems, mobile fund transferring services affords to deliver e-services without having users' bank account information or making them to be present at a bank branch in person. 

program

The Federal Government of Pakistan acted against COVID-19 via implementing lockdown strategies. This caused hardship on its citizens since people could not effort to stay in their homes and begin losing their jobs. To solve this problem and provide a financial relief package, the government devise an online portal for the EEC program. This program foresees the development of an online network, which provides a collaboration platform for key multi-stakeholders in the economy. The formation of this platform, the EEC program, brought together the relevant bodies and established public-private cooperation to aid people who are already living in poverty line or under it. In addition, this collaboration enabled the private as well as stateowned participants to leverage their organizational expertise in their relative industries to allocate funds and reach people who are in need in the most efficient way possible.

The process of integration was relatively straightforward in the context of Pakistan. The previously established link among NADRA, local banks, and the telecom providers offers an ease for mobile money transfer and recording transactions in Pakistan. While NADRA is designated to provide verification of the biometric and citizens' personal records, the telecom service providers expedite the mobile fund transfer over already operational banking infrastructure. During the application process, citizens simply provide their identifications and biometric information digitally in the EEC online portal, and this portal concurrently authenticates claimants' personal records from the NADRA database. Then, data related to a specific citizen's CNIC number is benched against the overall information that is provided by the citizen and NADRA for a second step authentication by the telecom companies. After successful authentication of records from both institutions, claimants receive a text alert on their registered mobile number about admissibility to the EEC program.

If a citizen found as an eligible candidate for the program, the EEC funds would be transferred to claimant's bank account. Simultaneously, the telecom service provider directs all the collected information and bank information to applicants' designated EEC mobile number. Afterward, the claimant can visit the most convenient point of sale (POS) or bank branch to collect the funds. In order to complete this step, citizens have to demonstrate that they received an appropriate and valid text from their mobile service provider in addition to their CNIC. In the process of bank branch or POS visits, citizens as well as the bank branch or POS employees, apply the government's standard operating guidelines that address preventative measures like social distancing and operating hours.

As an additional protection and fraud prevention mechanism, a claimant is obligated to visit the branch or POS that his or her choosing during a specific time. At the fundamental level, this enhances and supports maintaining social distancing, use hand sanitizer, and wear a face mask. On a more complex level, it provides an easy-to-track collected biometric verification, text message, and CNIC of an individual while branch or POS employee finishes handing out the money to the individual. When the fund is received by the citizen, and branch or POS finish the processing, the bank sends a validation communication to the receiver and EEC program administrators. This government public-private strategy enables the government to prevent the spread of the virus at a great scale and fiscally aid low-income families and citizens. In summary, the Pakistani government accomplishes to formula public-private cooperation amongst NADRA, telecom, and banking sectors, which proficiently and competently delivered 144 million PKR worth of financial funding to families in need via leveraging an online system, EEC program. This accomplishment demonstrates the conceivable benefits of public-private collaborations in the framework of strategy building while leveraging e-platforms to leverage state and private industry collaboration to support the Pakistani citizens and families, who are more vulnerable to adverse financial effects of the COVID-19. 


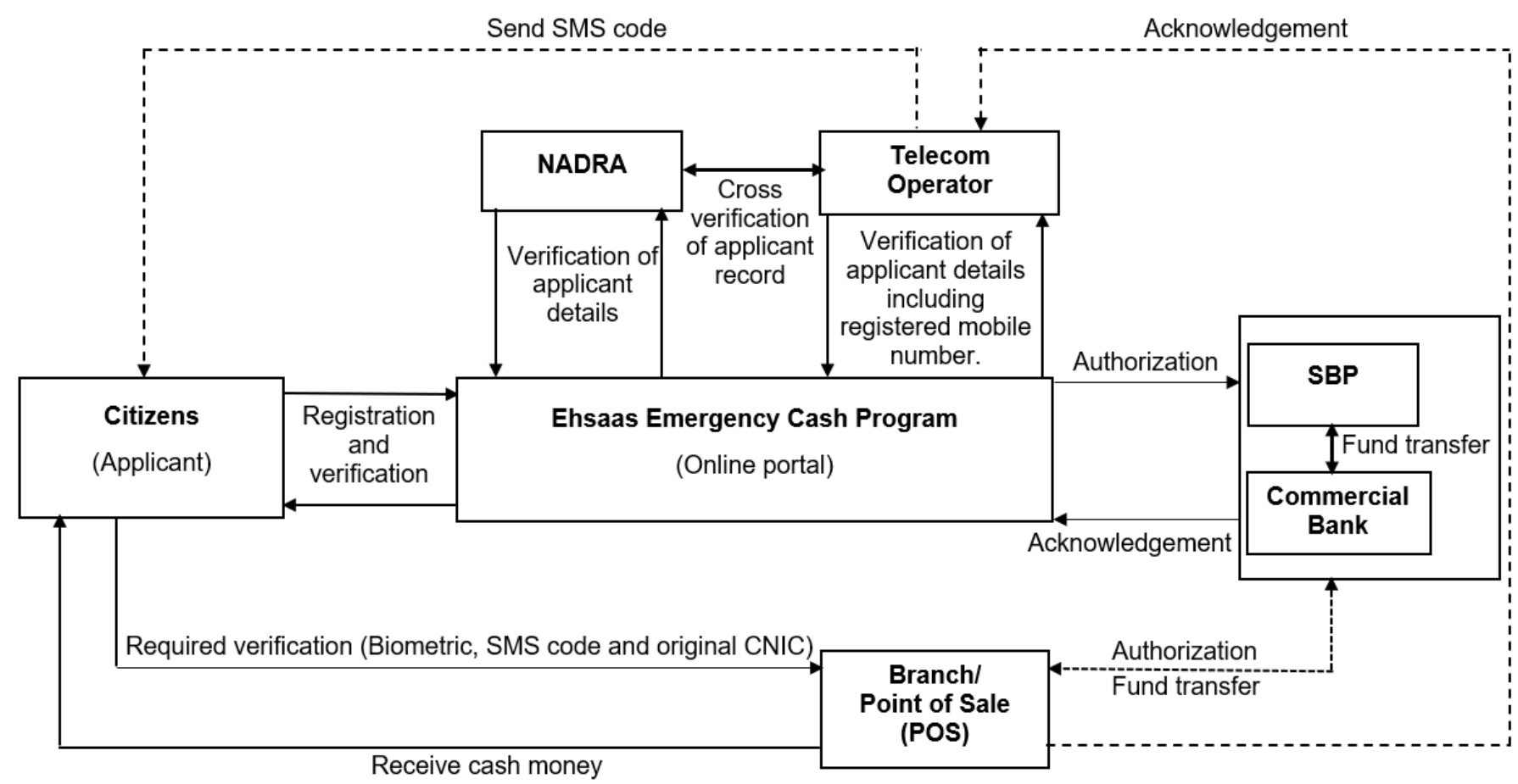

Figure 1. Public-private ICT-based collaboration initiative under the EEC program (Authors' own elaboration).

\section{CONCLUSION}

This study demonstrates that the successful ICT based public-private collaboration strategy, which is devised by the Pakistani government in the midst of the pandemic through mobile fund transfer program, greatly helped Pakistani government to aid its citizens. Through demonstrating the steps that are taken to create the EEC Program and how the program works, this study provides a blueprint for the nations, especially ones that are in South-Asia. In addition, this study's findings further support the importance of the public-private collaboration in the time of COVID-19. Demonstrating how did the EEC not only serve as a fund allocation system, but also empowered the implementation of social distance rules and enhanced the transparency in rapid transfer of remittance to support people, this study also provides a workable framework for the developing and emerging market countries.

\section{Policy recommendations}

Due to its revealing nature for the stages of public-private collaboration formation via ICT based program, the study can be utilized as a reference point to help policy makers to replicate similar strategies in various country and crisis management context to produce effective solutions. In the case of advance countries, policy makers may create larger and more autonomous networks through utilizing cutting-edge ICT technologies while aiming to reach larger populations through collaborating diverse bodies. On the other hand, in emerging markets and developing nations, policy makers may change certain aspects of the EEC program and adopt it base on their needs. For instance, they may utilize private industry initiatives as contractors rather than public-private collaborators. It may enable them to oversee the business dealings and fund allocation.

Another aspect that policy makers may want to consider is the secondary benefits of the ICT-based collaboration. First, it reduces face-to-face interaction time and frequency as compared to traditional methods. Citizens do not need to visit multiple different state offices and bank authorities to receive the fund and can get their financial aid with minimal interaction with others. It also supports the quarantine guidelines and application. Second, it creates a multi-stakeholder mechanism that holds the record for transactions in more than one entity. This ensures the prevention of fraud. Third, the time and labor cost of the demonstrated in this case relatively lower. Therefore, with increased efficiency and relatively less cost, governments can serve more citizens and create a larger positive impact. 


\section{Limitations and future work}

The present study has its own limitations, which may serve as future direction for researchers to extend this work. For instance, scholars, who are interested in similar topics, may employ quantitative research methodologies. One viable option could be crafting a survey and applying it to get insight on Pakistani families as well as citizens' perception on the Ehsaas Emergency Cash program and its effectiveness. Another direction could be conducting interviews with state and private-sector participants as well as administrators of the Ehsaas program. This may also help academics to get detailed information on the steps that have been established by the involved parties in order to reach an efficient and effective ICT collaboration in the Pakistan context.

Another limitation of the study is the scope. In this study, the authors specifically focus on to the Pakistan case. However, a follow-up replication study in the context of other developing, emerging, or advanced country settings could lead to a better understanding of the policy building, public-private, and COVID-19 preventative measures subjects. Also, this may permit scholars to expand on the relative strands of the literature by conducting comparison studies. This type of study would especially be valuable for providing a reflection on the best possible preventative exercises that are employed by governments all around the globe.

Acknowledgments: An initial version of short paper was presented in ICEGOV2020 conference, Athens, Greece. The authors would like to acknowledge the technical and financial support of Writing Lab, Institute for the Future of Education, Tecnologico de Monterrey, Mexico, in the production of this work.

Conflicts of Interest: The authors declare that they have no conflict of interest.

\section{REFERENCES}

1. Skargren $F$. What is the point of benchmarking e-government? An integrative and critical literature review on the phenomenon of benchmarking e-government. Inf. Polity. 2020;25:67-89.

2. Gobin-Rahimbux B, Cadersaib Z, Chooramun N, et al. A Systematic literature review on ICT architectures for smart Mauritian local council. Transforming Government: People, Process and Policy 2020;14:261-81.

3. Abbas A, Faiz A, Fatima A, et al. Reasons for the failure of government IT projects in Pakistan: A contemporary study. Proceedings of the 2017 International Conference on Service Systems and Service Management; 2017 Jul 31; Dalian, China. IEEE; 2017.

4. Avdic A and Lambrinos T. Modeling and illustrating requirement prioritization in public e-service development from a value-based perspective. EJEG. 2015;13:1-15.

5. Fougère $M$ and Solitander $N$. Dissent in consensusland: An agonistic problematization of multi-stakeholder governance. J. Bus. Ethics. 2020;164:683-99.

6. DiVito L, van Wijk J, Wakkee I. Governing collaborative value creation in the context of grand challenges: A case study of a public-private collaboration in the textile industry. Business and Society 2020:1-40.

7. Schnoll HJ. E-Government: Information, Technology, and Transformation: Information, Technology, and Transformation. Armony NY: M.E. Sharpe, 2015.

8. Pilemalm S, Lindgren I, Ramsell E. Emerging forms of inter-organizational and cross-sector collaborations in egovernment initiatives. Transforming Government: People, Process and Policy 2016;10.

9. Obi T. E-governance: a global perspective on a new paradigm. IOS Press; 2007.

10. Abbas A, Avdic A, Xiaobao $P$, et al. Strategic framework of collaboration in knowledge transfer of high-tech industries. Quality: Access to Success 2018;19:74-80.

11. Tubtimhin J and Pipe GR. Global e-governance: advancing e-governance through innovation and leadership. IOS Press; 2009.

12. Hassan MH, Lee J. Policymakers' perspective about e-government success using AHP approach. Transforming Government: People, Process and Policy 2019;13:93-118.

13. Shkarlet S, Oliychenko I, Dubyna M, et al. Comparative analysis of best practices in e-government implementation and use of this experience by developing countries. Administratie si Management Public 2020;34:118-36.

14. UN. E-Government survey 2020: Digital government in the decade of action for sustainable development. Available online: https://publicadministration.un.org/egovkb/Portals/egovkb/Documents/un/2020-Survey/2020\%20UN\%20EGovernment\%20Survey\%20(Full\%20Report).pdf (Accessed 2020 Aug).

15. Hermansson H. Disaster response in Turkey: Conditions promoting public-private collaboration and implications for effectiveness. Adm. Soc. 2019;51:1051-78.

16. Hooda A, Singla M. Reengineering as a strategic stance for e-governance success-mediating role of core competencies. Transforming Government: People, Process and Policy. 2020;14:205-35. 
17. Panwar H, Gupta P, Siddiqui MK, et al. Application of deep learning for fast detection of COVID-19 in X-Rays using nCOVnet. Chaos, Solitons \& Fractals 2020;138:109944.

18. Lau $\mathrm{H}$, Khosrawipour $\mathrm{V}$, Kocbach $\mathrm{P}$, et al. The positive impact of lockdown in Wuhan on containing the COVID-19 outbreak in China. J. Travel Med. 2020; 27: taaa037.

19. Lu D. Inside Wuhan's lockdown. NewScientist 2020; 245.

20. Worldometer. Coronavirus cases. Available online: https://www.worldometers.info/coronavirus/\#countries (Accessed on Jun 2020).

21. COVID. Coronavirus in Pakistan, http://covid.gov.pk (Accessed on 2020 Sep).

22. Mamun MA, Ullah I. COVID-19 suicides in Pakistan, dying off not COVID-19 fear but poverty?-The forthcoming economic challenges for a developing country. Brain, Behavior, and Immunity. 2020;87:163-6.

23. Khan N, Naushad M, Akbar A, et al. Critical review of COVID-2019 in Pakistan and its impact on Pakistan economy. SSRN 2020.

24. International Monetary Fund. Five Charts that Illustrate COVID-19's Impact on the Middle East and Central Asia. Available online: https://www.imf.org/en/News/Articles/2020/07/14/na071420-five-charts-that-illustrate-covid19simpact-on-the-middle-east-and-central-asia (Accessed on $2021 \mathrm{Feb}$ ).

25. Rasheed R, Rizwan A, Javed H, et al. Socio-economic and environmental impact of COVID-19 pandemic in Pakistan-An integrated analysis. Environ. Sci. Pollut. 2021.

26. Bukhari N, Rasheed H, Nayyer B, et al. Pharmacists at the frontline beating the COVID-19 pandemic. J. Pharm Policy Pract. 2020;13.

27. Farquhar $\mathrm{J}$, Michels $\mathrm{N}$, et al. Triangulation in industrial qualitative case study research: Widening the scope. Industrial Market. Ind. Mark. Manag. 2020;160-7.

28. Vissak T. Recommendation for using the case study method in international business research. Qual. Rep. 2010; 15: $370-88$.

29. Ar AY, Abbas A. Corporate social responsibility projects to supports multinational enterprises reputation building efforts in Mexico. J. Public Aff. Forthcoming 2020; e2495.

30. Siggelkow N. Persuasion with case studies. Academy of Management 2007;50:20-4.

31. Eisenhardt MK. Agency theory: An assessment and review. Acad of Manage Rev. 1989;14:57-74.

32. Hillebrand B, Kok AR, Biemans WG. Theory-testing using case studies: A comment on Johnston, Leach, and Liu. Ind. Mark. Manag. 2001;30:160-70.

33. Jensen JL, Rodgers R. Cumulating the intellectual gold of case study research. Public Adm. Rev. 2001;61:235-46.

34. NADRA. National Database and Registration Authority. Available online: https://www.nadra.gov.pk/about-us (Accessed on $2021 \mathrm{Fev}$ ).

35. Afshan S, Sharif A. Acceptance of mobile banking framework in Pakistan. Telemat. Inform. 2016;33:370-87.

36. Siyal AW, Ding D, Siyal S. M-banking barriers in Pakistan: a customer perspective of adoption and continuity intention. Data Technol. Appl. 2019;53:58-84.

2021 by the authors. Submitted for possible open access publication under the terms and conditions of the Creative Commons Attribution (CC BY NC) license (https://creativecommons.org/licenses/by-nc/4.0/). 